\title{
DETERMINATION OF A DISTRIBUTION IN A SOURCE TERM OF A TIME FRACTIONAL DIFFUSION-WAVE EQUATION
}

\author{
ANDRZEJ LOPUSHANSKY AND HALYNA LOPUSHANSKA
}

\begin{abstract}
We study the inverse Cauchy problem to a time fractional diffusion-wave equation with distributions in right-hand sides. This problem is to find a generalized solution of direct problem and an unknown time-dependent part of a source from the space of distributions. The unique solvability of the problem is established.
\end{abstract}

Mathematics subject classification (2010): 35S15.

Keywords and phrases: Distribution, fractional derivative, inverse problem, Green vector-function.

\section{REFERENCES}

[1] T. S. Aleroev, M. Kirane, S. A. Malik, Determination of a source term for a time fractional diffusion equation with an integral type over-determination condition, Electronic J. of Differential Equations 2013 (270), (2013), 1-16.

[2] J. Cheng, J. Nakagawa, M. Yamamoto and T. Yamazaki, Uniqueness in an inverse problem for a one-dimentional fractional diffusion equation, Inverse Problems 25, (2009), 1-16.

[3] M. M. DJRbashian, A. B. Nersessyan, Fractional derivatives and Cauchy problem for differentials of fractional order, Izv. AN Arm. SSR, Matematika 3 (1), (1968), 3-29.

[4] S. D. Eidelman, S. D. IVAS YShen, A. N. KochubeI, Analytic methods in the theory of differential and pseudo-differential equations of parabolic type, Basel-Boston-Berlin, Birkhauser Verlag, 2004.

[5] M. M. EL-BORAI, On the solvability of an inverse fractional abstract Cauchy problem, LJRRAS 4, (2001), 411-415.

[6] V. V. Gorodets KiI, V. A. Litovchenko, The Cauchy Problem for pseudodifferential equations in spaces of generalized functions of type $S^{\prime}$, Dop. NAS of Ukraine 10, (1992), 6-9.

[7] Y. Hatano, J. Nakagawa, Sh. Wang And M. Yamamoto, Determination of order in fractional diffusion equation, Journal of Math-for-Industry 5A, (2013), 51-57.

[8] M. I. ISMAILOV, Inverse source problem for a time-fractional diffusion equation with nonlocal boundary conditions, Applied Mathematical Modeling 40 (7/8), (2016), 4891-4899.

[9] JA. JANNO, Determination of the order of fractional derivative and a kernel in an inverse problem for a generalized time fractional diffusion equation, Electronic J. of Differential Equations 2016 (199), (2016), 1-28, http://ejde.math.txstate.edu or http://ejde.math.unt.edu/2016/199.

[10] A. N. KochUBEI, A Cauchy problem for equations of fractional order, Differential Equations 25, (1989), 967-974.

[11] A. LOPUSHANSKY, H. LOPUSHANSKA, Inverse source Cauchy problem to a time fractional diffusionwave equation with distributions, Electronic J. of Differential Equations 2017 (182), (2017), 1-14.

[12] YU. LuCHKo, Boundary value problems for the generalized time-fractional diffusion equation of distributed order, Fract. Calc. Appl. Anal. 12 (4), (2009), 409-422.

[13] M. I. Matijchu K, Parabolic and elliptic problems in Dini spaces, Chernivtsi, 2010.

[14] M. M. Meerschaert, N. Erkan, P. Vallais amy, Fractional Cauchy problems on bounded domains, Ann. Probab. 37, (2009), 979-1007.

[15] V. A. Mikhailets, A. A. Murach, Hormander spaces, unterpolation, and elliptic problems, Birkhauser, Basel, 2014. 
[16] J. NAKAgawa, K. SAKAмото AND M. YAMAмото, Overview to mathematical analysis for fractional diffusion equation - new mathematical aspects motivated by industrial collaboration, Journal of Math-for-Industry 2A, (2010), 99-108.

[17] W. Rundell, X. XU AND L. ZUO, The determination of an unknown boundary condition in fractional diffusion equation, Applicable Analysis 1, (2012), 1-16.

[18] G. E. SHILov, Mathematical Analyses. Second special curse, Nauka, Moskow, 1965, Russian.

[19] A. A. Voroshylov, A. A. Kilbas, Conditions of the existence of classical solution of the Cauchy problem for diffusion-wave equation with Caputo partial derivative, Dokl. Ak. Nauk 414 (4), (2007), $1-4$.

[20] A. A. Voroshylov, A. A. Kilbas, Conditions of the existence of a classical solution of a Cauchy type problem for the diffusion equation with the Riemann-Liouville partial derivative, Differential Equations, 44 (6), (2008), 789-806.

[21] Y. ZHANG AND X. XU, Inverse source problem for a fractional diffusion equation, Inverse Problems, 27, (2011), 1-12. 